Article

\title{
Bioshell Calcium Oxide (BiSCaO) Ointment for the Disinfection and Healing of Pseudomonas aeruginosa-Infected Wounds in Hairless Rats
}

\author{
Tomohiro Takayama ${ }^{1, *}$, Masayuki Ishihara ${ }^{2}$, Shingo Nakamura ${ }^{2} \mathbb{D}$, Yoko Sato $^{3}$, \\ Sumiyo Hiruma ${ }^{2}$, Koichi Fukuda ${ }^{2}$, Kaoru Murakami ${ }^{1}$ and Hidetaka Yokoe ${ }^{1}$ \\ 1 Department of Oral and Maxillofacial Surgery, National Defense Medical College, 3-2 Namiki, Tokorozawa, \\ Saitama 359-8513, Japan; murakami@ndmc.ac.jp (K.M.); yokoe@ndmc.ac.jp (H.Y.) \\ 2 Division of Biomedical Engineering, Research Institute, National Defense Medical College, 3-2 Namiki, \\ Tokorozawa, Saitama 359-8513, Japan; ishihara@ndmc.ac.jp (M.I.); snaka@ndmc.ac.jp (S.N.); \\ res337@ndmc.ac.jp (S.H.); khf05707@nifty.com (K.F.) \\ 3 Division of Statistical Analysis, Research Support Center, Shizuoka General Hospital, 4-27-1 Kita-ando, \\ Aoi-ku, Shizuoka 420-8527, Japan; sato.yoko.shiz@gmail.com \\ * Correspondence: taka01@ndmc.ac.jp; Tel.: +81-429-95-1925 (ext. 3617)
}

Received: 13 May 2020; Accepted: 9 June 2020; Published: 11 June 2020

\begin{abstract}
Bioshell calcium oxide (BiSCaO) possesses deodorizing properties and broad microbicidal activity. This study aimed to investigate the application of $\mathrm{BiSCaO}$ ointment for the prevention and treatment of infection in chronic wounds in healing-impaired patients, without delaying wound healing. The bactericidal activities of $0.04,0.2,1$, and $5 \mathrm{wt} \% \mathrm{BiSCaO}$ ointment, $3 \mathrm{wt} \%$ povidone iodine ointment, and control (ointment only) were compared to evaluate the in vivo disinfection and healing of Pseudomonas aeruginosa-infected wounds in hairless rats. Treatment of the infected wounds with $0.2 \mathrm{wt} \% \mathrm{BiSCaO}$ ointment daily for 3 days significantly enhanced wound healing and reduced the in vivo bacterial counts compared with povidone iodine ointment and control (no wound cleaning). Although $5 \mathrm{wt} \%$ BiSCaO ointment provided the lowest bacterial counts during 3 days' treatment, it delayed wound healing. Histological examinations showed significantly advanced granulation tissue and capillary formation in wounds treated with $0.2 \mathrm{wt} \% \mathrm{BiSCaO}$ ointment for 3 days compared to wounds treated with the other ointments. This study suggested that using $0.2 \mathrm{wt} \% \mathrm{BiSCaO}$ ointment as a disinfectant for infected wounds and limiting disinfection to 3 days may be sufficient to avoid the negative effects of $\mathrm{BiSCaO}$ on wound repair.
\end{abstract}

Keywords: bioshell calcium oxide (BiSCaO); bactericidal activity; ointment; infected wound; wound repair

\section{Introduction}

Wound healing is the result of a series of correlated cellular processes that are initiated by cytokines and growth factors [1]. These cellular processes are suppressed by tissue bacterial bioburden [2], which may contribute to degradation of the cytokines and growth factors [3]. Several studies have shown that the level of bacterial bioburden can exceed $1 \times 10^{6}$ per gram of tissue [4]. Such high levels of tissue bacteria can be present without clinical signs of infection and can unfavorably affect wound healing [5].

Pseudomonas (P.) aeruginosa is a major nosocomial microbe and opportunistic pathogen that can infect wounds and is known to play a role in impaired wound healing [6]. In a chronic granulating wound, systemically administered antibiotics do not effectively decrease the level of bacteria [6]. Furthermore, the topical use of antibiotics used systemically for purposes other than wound infection is discouraged because of an increased risk for allergies and the potential for drug resistance [7]. 
Antiseptics and non-antibiotic antimicrobials, such as povidone iodine and weakly acidic hypochlorous acid $(\mathrm{HClO})$ solution, have been demonstrated to be cytotoxic to the cellular components of wound healing [8-10]. Therefore, a topical antimicrobial that can decrease the bacterial bioburden in chronic wounds without inhibiting the wound-healing process is a therapeutic imperative [6].

Calcium oxide $(\mathrm{CaO})$ is generally produced from limestone and is an important inorganic compound used in various industries as an adsorbent for toxic waste remediation and as an alkalization agent. However, $\mathrm{CaO}$ derived from limestone contains harmful impurities and rapidly generates heat upon hydration [11,12]. Scallop shells are an alternative readily available source of $\mathrm{CaO}$ that is used as a food additive, as well as in plastering and paving materials. However, $\mathrm{CaO}$ derived from scallop shells also contains harmful impurities such as heavy metals and thus most scallop shells are treated as industrial waste and piled on the shores of harvesting districts in Japan, causing serious problems such as offensive odors and soil pollution [13].

Heated scallop shell powder (SSP) exhibits strong microbicidal activities [14]. SSP heated at $>1000{ }^{\circ} \mathrm{C}$, then ground further, exhibits broad microbicidal action against various viruses, bacteria, heat-resistant bacterial spores, fungi and biofilms [12-19], and is used as an additive to prolong the shelf life of food [14,19].

Slurries of SSP comprising particles with diameters in the range of $60-900 \mathrm{~nm}$ are prepared by grinding shells heated at $>1100{ }^{\circ} \mathrm{C}$ with a wet bead grinding mill [14] and suspending the powder in sterile saline. The main component of this heated shell powder slurry is calcium hydroxide $\left(\mathrm{Ca}(\mathrm{OH})_{2}\right)$. Similarly, most commercially available heated shell powder products used as food additives comprise $\mathrm{Ca}(\mathrm{OH})_{2}$. In a previous study, we used commercially available scallop shell powders with an average diameter of $6 \mu \mathrm{m}$ heated at $1450{ }^{\circ} \mathrm{C}(\mathrm{BiSCaO})$ purchased from Plus Lab Corp., Kanagawa, Japan. According to the manufacturer, the content of $\mathrm{CaO}$ exceeded $99.5 \%[20,21]$.

Several techniques have been developed for cleaning chronic infected wounds, leg ulcers and pressure ulcers using water or saline at $\mathrm{pH}$ values of between 5.5 and 6.5 and at temperatures of between $35^{\circ} \mathrm{C}$ and $45^{\circ} \mathrm{C}$ [22-24]. Weakly acidic ( $\mathrm{pH}$ 5.5-6.5) hypochlorous acid ( $\left.\mathrm{HClO}\right)$ solution generated by mixing sodium hypochlorite and weakly acidic water or saline has excellent In Vitro bactericidal properties $[25,26]$. Daily wound cleaning with $\mathrm{HClO}$ solution ( $\mathrm{pH} 6.5$ ) for 12 days decreased the P. aeruginosa bioburden in infected wounds in $\mathrm{db} / \mathrm{db}$ diabetic mice but wound repair was delayed [27].

Limiting disinfection treatment with both $\mathrm{HClO}$ and chitin-nanofiber sheet-immobilized silver nanoparticles (CNFS/Ag NPs) to 3 days [28-30] may suppress these negative effects on wound repair [31]. We previously showed that treating P. aeruginosa-infected wounds on hairless rats with BiSCaO suspension $(0.2 \mathrm{wt} \%, \mathrm{pH} 12.3)$ once daily for 3 days and covering the wound with CNFS significantly decreased the P. aeruginosa bioburden and enhanced wound repair [32].

The aim of the present study was to test the originally proposed various concentrations of $\mathrm{BiSCaO}$ in an ointment rather than in a slurry, with the eventual aim of preventing and treating infection in chronic wounds in healing-impaired patients, without delaying wound healing.

\section{Results}

\subsection{Bactericidal Activities of Various Concentrations of BiSCaO and Povidone Iodine Ointments In Vitro}

The in vitro bactericidal activities of different concentrations of $\mathrm{BiSCaO}$ ointments and $3 \mathrm{wt} \%$ povidone iodine ointments against $P$. aeruginosa were tested by counting the viable bacterial colonies after treatment. The colonies of $P$. aeruginosa were completely eradicated after exposure to more than $0.2 \mathrm{wt} \% \mathrm{BiSCaO}$ after $10 \mathrm{~min}$, but some colonies survived after exposure to $0.04 \mathrm{wt} \% \mathrm{BiSCaO}$ and $3 \mathrm{wt} \%$ providone iodine ointments (Shionogi Co., Ltd., Osaka, Japan) after 10 and $30 \mathrm{~min}$. All 0.04, $0.2,1$ and $5 \mathrm{wt} \%$ BiSCaO ointments, and $3 \mathrm{wt} \%$ providone iodine ointment, completely eradicated the colonies after $60 \mathrm{~min}$ whereas control ointment alone did not decrease P. aeruginosa after $1 \mathrm{~h}$ (Figure 1 ). 


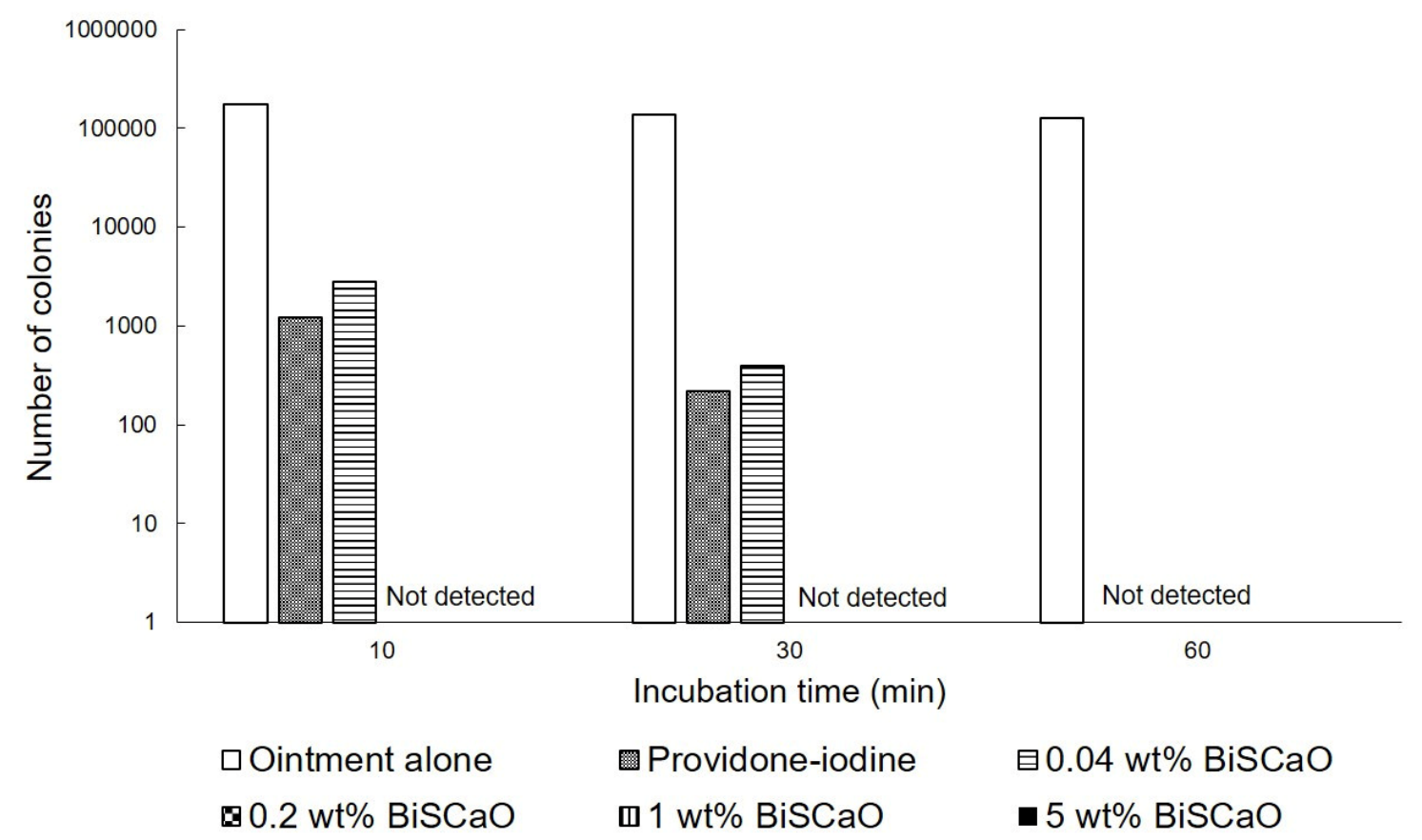

Figure 1. In vitro bactericidal activity of each ointment. P. aeruginosa was exposed to $0.04,0.2,1$ and $5 \mathrm{wt} \% \mathrm{BiSCaO}$ ointments, $3 \mathrm{wt} \%$ providone iodine ointment, or control ointment-coated plates and incubated for 5, 10, 20 and $30 \mathrm{~min}$ at room temperature. The bacterial colonies were counted to measure the minimal bactericidal concentration of each disinfectant $(n=6)$.

\subsection{Disinfection of P. aeruginosa-Infected Wounds with BiSCaO and Povidone Iodine Ointments In Vivo}

All animals tolerated the creation of P. aeruginosa-infected wounds, and daily wound cleaning with saline and application of ointment without complications. No signs of acute inflammation, abscess formation, or seroma accumulation were seen on the infected wound sites on the 9th day after surgery and infection.

Before cleaning the wound and applying each ointment (Day 0$), 2.5 \pm 0.4\left(\times 10^{5}\right)$ colony forming units (CFU) of P. aeruginosa were inoculated into each wound. On Day 1 after treating the wounds with $0.04,0.2,1.0$ or $5.0 \mathrm{wt} \% \mathrm{BiSCaO}, 3 \mathrm{wt} \%$ providone iodine-ointment, or control ointment, the mean viable cell counts were $3.14 \times 10^{4}, 4.18 \times 10^{4}, 4.15 \times 10^{4}, 3.3 \times 10^{4}, 3.24 \times 10^{4}$, and $5.4 \times 10^{4}$, respectively, and are not significantly different. The mean viable cell count in non-cleaned wounds was $2.6 \times 10^{5}$ $\mathrm{CFU}$, which is significantly higher than the other groups. These results show that the bioburden was effectively decreased by cleaning with saline and treating with $\mathrm{BiSCaO}$ immediately following cleaning whereas the bioburden slightly increased in the non-cleaned wound group. On Day 2, the mean viable cell count of the $5 \mathrm{wt} \% \mathrm{BiSCaO}$ ointment group was lower than the other groups. On Days 3 and 6 , the mean viable cell counts of the $0.2,1.0$ and $5 \mathrm{wt} \% \mathrm{BiSCaO}$ ointment groups were significantly lower than those of the $0.04 \mathrm{wt} \%$ BiSCaO-ointment, povidone iodine ointment, control ointment, and non-cleaned wound groups. On Day 9, all the P. aeruginosa colonies were eradicated in all but the non-cleaned wound group, which had a mean viable cell count of $7.8 \times 10^{3}$ (Figure 2). These results suggested that cleaning the infected wounds with saline and application of $0.2,1$ or $5 \mathrm{wt} \% \mathrm{BiSCaO}$ ointment for 3 days significantly decreased the mean viable cell counts on Days 3 and 6 compared to the other groups, and there were no significant differences between the three concentrations of BiSCaO. 


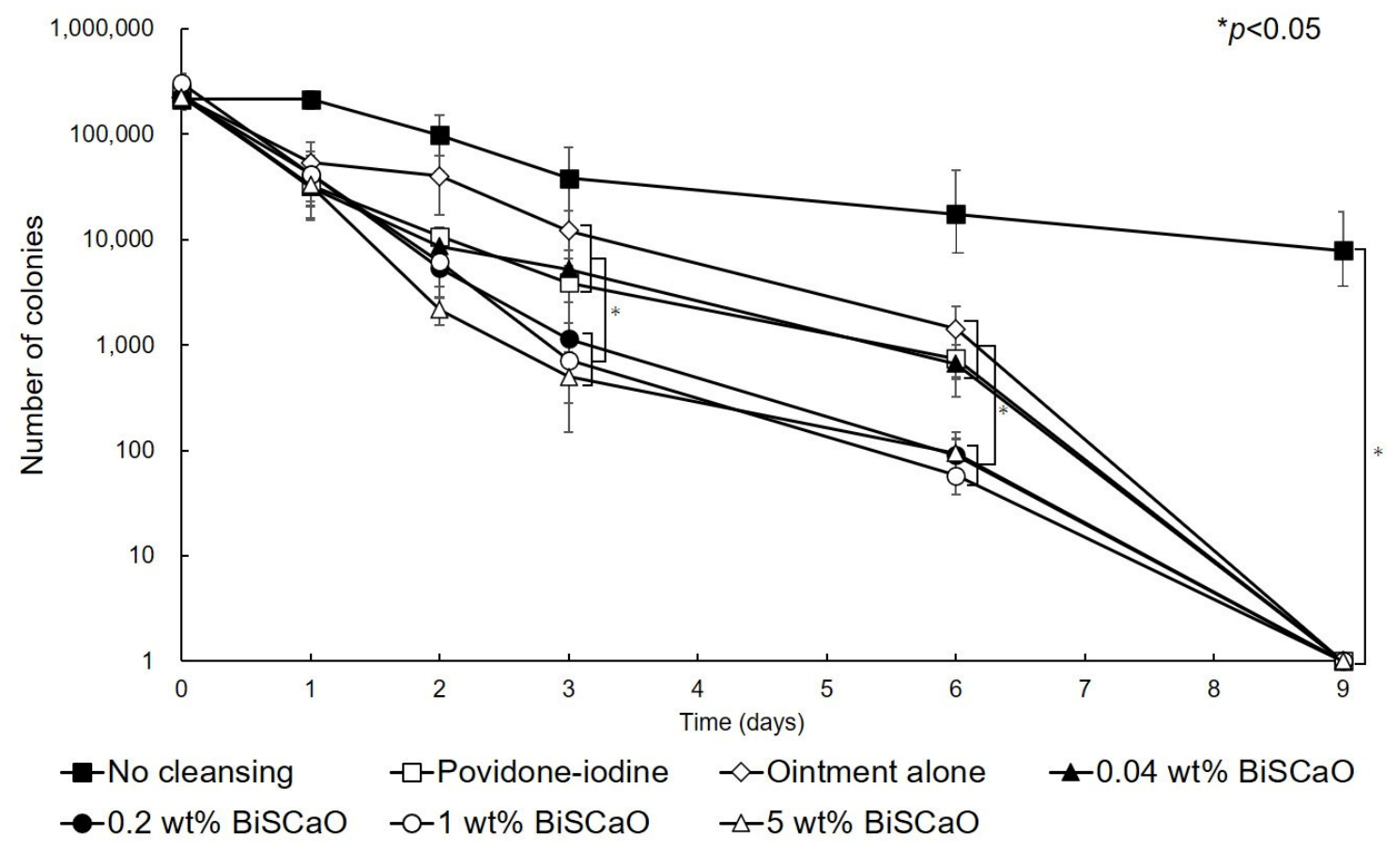

Figure 2. Eradication of $P$ aeruginosa colonies from wounds treated with disinfectant In Vivo. The $P$. aeruginosa-infected wounds on hairless rats were cleaned with saline, then each ointment was applied once daily on Days 1-3 and covered with chitin nanofiber sheets (CNFS). Wounds cleaned with saline once daily on Days 4-9 were covered with CNFS. After cleaning with saline, the contents of the wounds on the indicated day after wound creation were collected and the viable cell counts were measured. Data are presented as mean \pm standard deviation $(\mathrm{SD}, n=6)$.

\subsection{Healing of P. aeruginosa-Infected Wounds by Applying Disinfectants In Vivo}

The open wound areas for all groups was defined as $100 \%$ on Day 0 based on digital photographs (Figure 3) and the change in open wound area was monitored with time (Figure 4). There were no significant differences in wound closure rates on Day 2 between the groups (Figures 3 and 4). On Day 3 , the open wound areas of the $0.2 \mathrm{wt} \% \mathrm{BiSCaO}$ ointment $(76 \%)$ and $1 \mathrm{wt} \% \mathrm{BiSCaO}$ ointment $(78 \%)$ groups were significantly smaller than those of the providone iodine ointment $(97 \%), 5 \mathrm{wt} \% \mathrm{BiSCaO}$ ointment (101\%), control ointment (94\%) and non-cleaned groups (103\%). On Days 6 and 9, the open wounds of the 0.2 and $1 \mathrm{wt} \% \mathrm{BiSCaO}$ ointment groups were significantly smaller than those of the other groups. Although the result did not indicate wound contraction, which is an important factor for acceleration of wound healing [33-35], BiSCaO ointment might induce wound contraction in addition to disinfection for $P$. aeruginosa. These results suggested that application of 0.2 and $1 \mathrm{wt} \% \mathrm{BiSCaO}$ ointment for 3 days may help eradicate $P$. aeruginosa and aid wound repair. 


\begin{tabular}{|c|c|c|c|c|c|c|}
\hline & Day0 & Day1 & Day2 & Day3 & Day6 & Day9 \\
\hline No cleansing & & $\therefore$ & $\therefore$ & & (4) & (2) \\
\hline Ointment alone & & 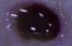 & & & & is. \\
\hline Providone-iodine & & & & & & (3) \\
\hline $0.04 \mathrm{wt} \% \mathrm{BisCaC}$ & & & & & & 2 \\
\hline $0.2 \mathrm{wt} \% \mathrm{BisCaO}$ & & & 4 & 6 & 9 & 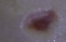 \\
\hline $1 \mathrm{wt} \% \mathrm{BisCaO}$ & & & & & & $\Leftrightarrow$ \\
\hline $5 \mathrm{wt} \% \mathrm{BisCaO}$ & & & & & & 5 \\
\hline
\end{tabular}

Figure 3. Digital photographs of the open areas of infected wounds. The P. aeruginosa-infected wounds on hairless rats were cleaned with saline, then each ointment was applied once daily on Days 1-3 and covered with CNFS. Wounds cleaned with saline once daily on Days 4-9 were covered with CNFS. The wounds were photographed before cleaning on Days $0,1,2,3,6$ and 9 to allow assessment of the rate of wound healing. The images represent wounds $(n=6)$ of the indicated treatment group on the indicated day.

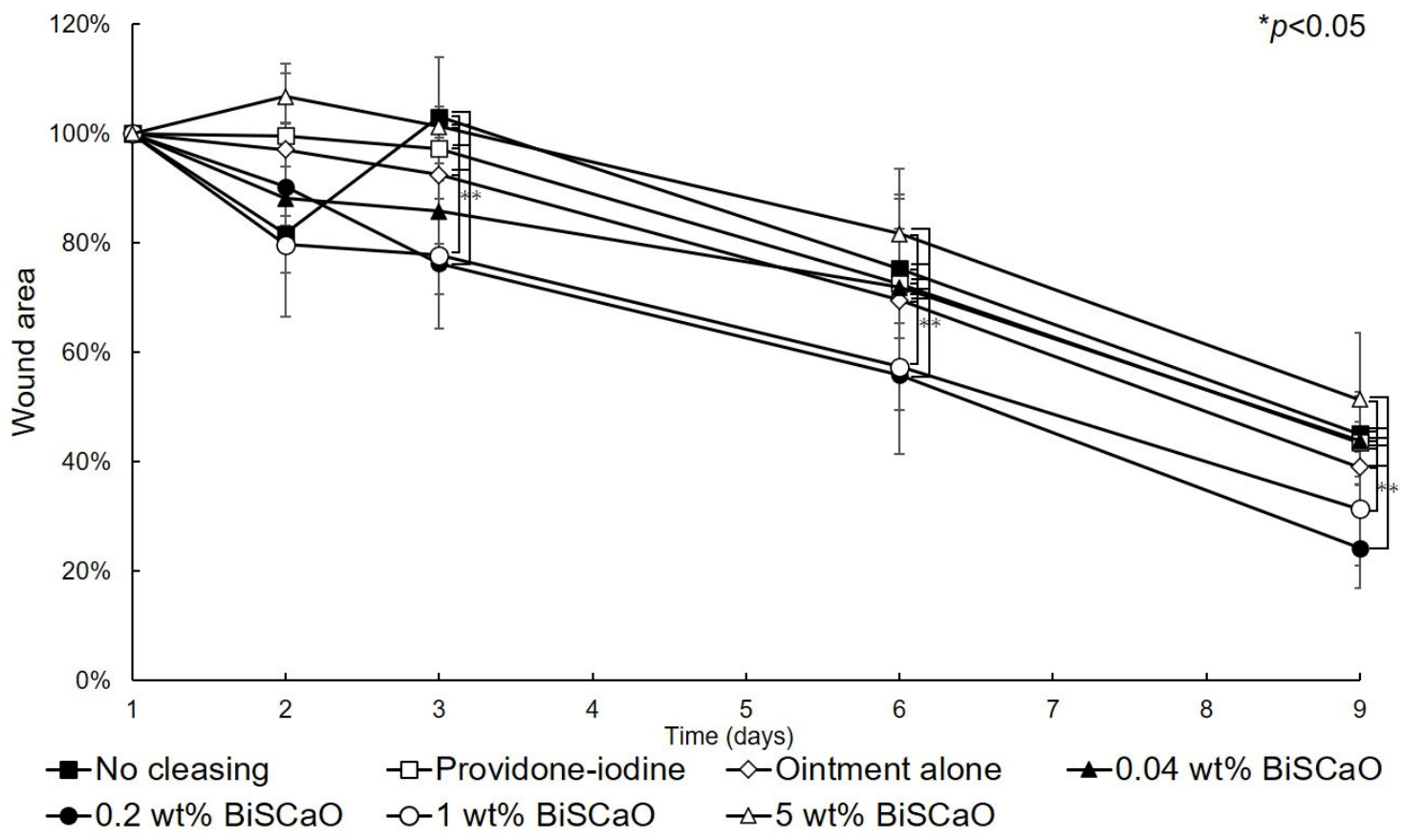

Figure 4. Rate of healing of open wounds. The area of the open wounds on Day 1 was defined as $100 \%$, and the relative open wound area of each group was calculated using the digital photographs in Figure 3. Data are presented as mean $\pm \operatorname{SD}(n=6) .{ }^{*} p<0.05$; Tukey's $t$-test. 


\subsection{Histological Analyses}

Histological examinations on Day 9 showed that granulation tissue formation and vascularization (Figure 5) in the 0.2 and $1 \mathrm{wt} \% \mathrm{BiSCaO}$ ointment groups were significantly higher than those of the other groups (Table 1). Furthermore, CD-34-stained immunophotographs (Figure 6) confirmed capillary densities of each groups.
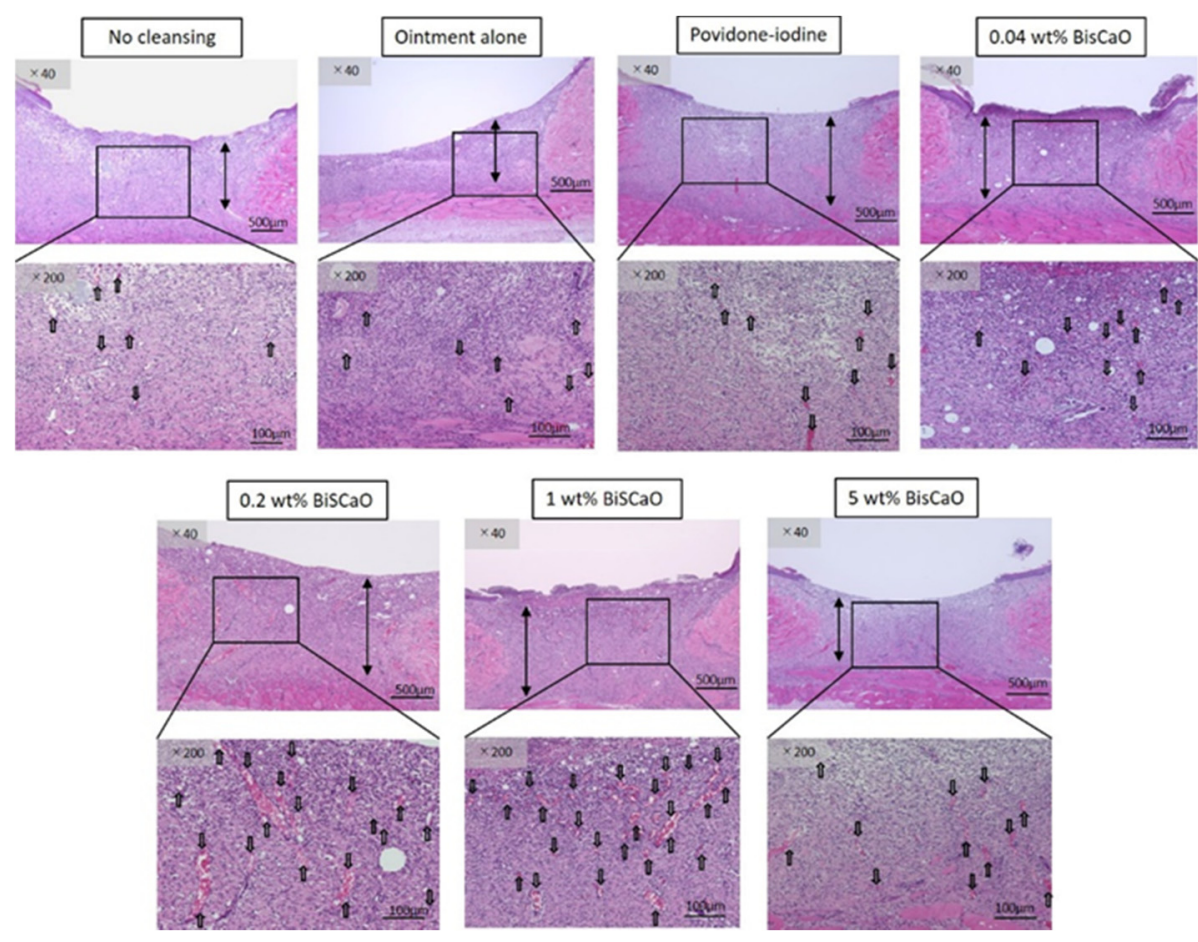

Figure 5. Histological examination of granulation tissue and capillary formation in each treatment group. The skin surrounding the infected wounds in each treatment group on Day 9 was harvested, processed for hematoxylin-eosin (H\&E) staining, and microphotographed $(n=6)$ (magnification: 40X, $200 \times)$, the arrows show blood vessels.

The bars show generated granulation tissues and the arrows show blood vessels. The microphotographs represent the wounds for the indicated treatment group. Analysis of these microphotographs provides the data given in Table 1.

Table 1. Histological examination of the length of granulation tissue and capillary formation.

\begin{tabular}{ccc}
\hline Disinfectant in Ointments & Length of Granulation Tissue $(\mu \mathrm{m})$ & $\begin{array}{c}\text { Capillary Formation } \\
\text { (Capillary Number/Image) }\end{array}$ \\
\hline No cleansing & $920 \pm 95$ & $7 \pm 5$ \\
Ointment alone & $940 \pm 100$ & $13 \pm 4$ \\
Providone-iodine & $980 \pm 80$ & $9 \pm 3$ \\
$0.04 \mathrm{wt} \% \mathrm{BiSCaO}$ & $1020 \pm 60$ & $14 \pm 6$ \\
$0.2 \mathrm{wt} \% \mathrm{BiSCaO}$ & $1160 \pm 85^{*}$ & $35 \pm 10^{*}$ \\
$1 \mathrm{wt} \% \mathrm{BiSCaO}$ & $1120 \pm 75^{*}$ & $31 \pm 8^{*}$ \\
$5 \mathrm{wt} \% \mathrm{BiSCaO}$ & $950 \pm 65$ & $11 \pm 6$ \\
\hline
\end{tabular}

The data represent the mean \pm SD. In length of granulation tissue, ${ }^{*} p<0.05$ vs. no cleansing and ointment alone $(n=6)$, in capillary formation, ${ }^{*} p<0.05$ vs. no cleansing and providone-iodine $(n=6)$. 


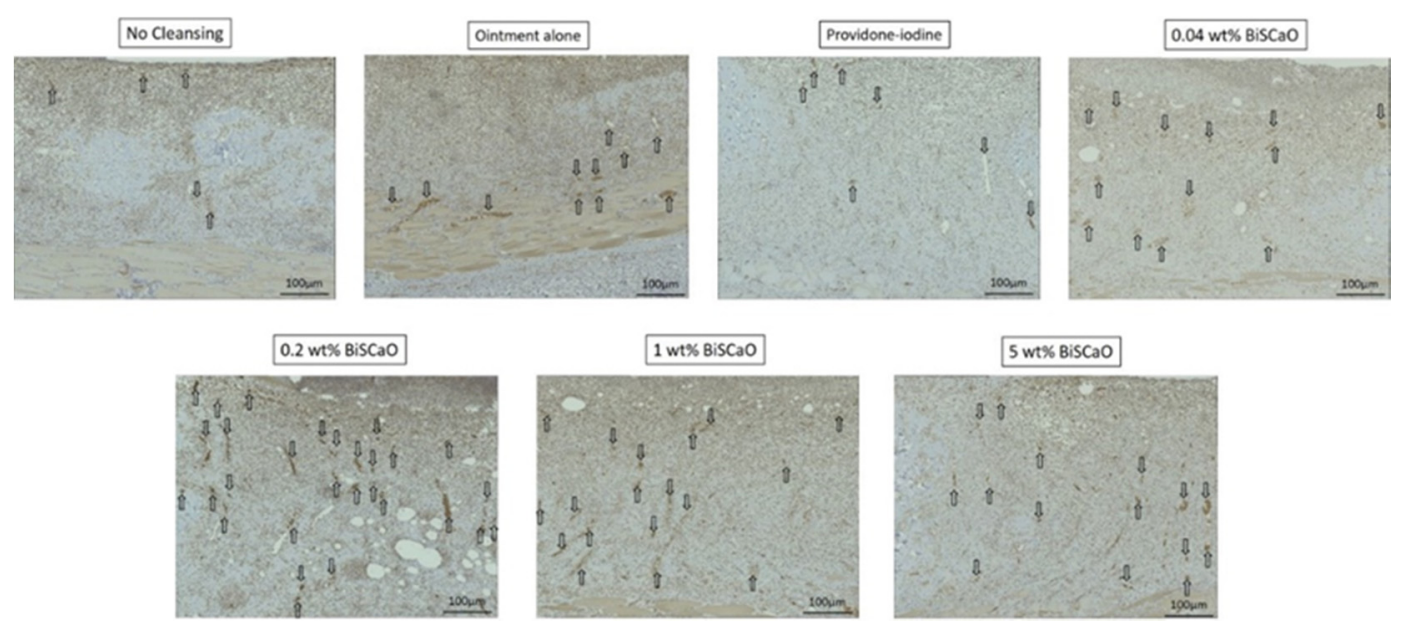

Figure 6. Histological examination of capillary formation with CD-34-stained immunophotographs in each treatment group. The skin surrounding the infected wounds in each treatment group on Day 9 was harvested, processed for CD 34-staining, and microphotographed $(n=6)$ (magnification: $200 \times$ ). The arrows show blood vessels. The microphotographs represent the wounds for the indicated treatment group. Analysis of these microphotographs provides confirmation of the data given in Table 1.

\section{Discussion}

The infection of wounds with P. aeruginosa is a major complication in clinical settings. In this study, in vitro bactericidal tests against $P$. aeruginosa showed complete eradication within 15 min of treatment with $0.2,1$ and $5 \mathrm{wt} \% \mathrm{BiSCaO}$ ointments but $60 \mathrm{~min}$ with $0.04 \mathrm{wt} \% \mathrm{BiSCaO}$ and $3 \mathrm{wt} \%$ povidone iodine ointments (Figure 1). We evaluated bactericidal activity and wound healing in vivo by cleaning $P$. aeruginosa-infected wounds on hairless rats with saline, applying each ointment, and covering with CNFS for 3 days. Each subsequent day for 6 days, the wounds were cleaned with saline, each ointment was applied, and the wound was covered with CNFS. The results suggested that applying $0.2-1 \mathrm{wt} \% \mathrm{BiSCaO}$ ointment for 3 days to the infected wounds significantly enhanced disinfection and wound healing in vivo, compared with the effects of povidone iodine ointment and control ointment. Histological examination showed significantly advanced formation of granulation tissue and capillaries following application of $0.2-1 \mathrm{wt} \% \mathrm{BiSCaO}$ to wounds for 3 days. Our previous study on FGF-containing photocrosslinkable chitosan hydrogel as wound dressing showed that wound contraction was an important factor for acceleration of wound healing [33-35]. It is possible $\mathrm{BiSCaO}$ ointment might induce wound contraction in addition to disinfection for P. aeruginosa, although we do not have direct data on the effect of $\mathrm{BiSCaO}$ on contraction and/or epithelialization. Furthermore, treatment with each ointment for 3 days did not produce signs of complications, as confirmed by histological analysis of wound skin harvested on Day 9. These results suggested that limiting disinfection by BiSCaO treatment to 3 days may be appropriate in a clinical situation, such as for the prevention and treatment of infection of chronic wounds in healing-impaired patients. We suggest that $0.2 \mathrm{wt} \% \mathrm{BiSCaO}$ ointment is optimal in terms of cost-effectiveness and safety.

Systemically administered antibiotics do not effectively decrease the level of bacteria in a chronic granulating wound because of an increased risk of developing allergies and the potential for selection of bacteria resistant to the drug [6,7] Antiseptics and non-antibiotic antimicrobials such as povidone-iodine, silver sulfadiazine, silver nanoparticles, mafenide acetate cream, and weakly acidic hypochlorous acid $(\mathrm{HClO})$ solution have been demonstrated to be cytotoxic to the cellular components of wound healing. On the other hand, hydrogel dressings with antioxidant functions have emerged and are proven to accelerate wound healing, especially for chronic wound repair [36,37].

Clinical antiseptics such as povidone iodine and $\mathrm{HClO}$ are cytotoxic to the cellular components of wound healing and high concentrations are required for disinfection [7-9]. Therefore, a topical 
disinfectant that can decrease the bacterial bioburden of chronic wounds without inhibiting the wound-healing process is a therapeutic imperative. Although both $\mathrm{BiSCaO}$ and commercially available heated SSP-Ca $(\mathrm{OH})_{2}$ are poorly water-soluble at strong alkaline $\mathrm{pH}(\mathrm{pH} \geq 12), \mathrm{BiSCaO}$ and SSP-Ca(OH $)_{2}$ suspensions in water generate a strong base, which is the primary mechanism for their microbicidal activities. The high disinfection activity of suspensions of $\mathrm{BiSCaO}$ and SSP-Ca(OH $)_{2}$ particles might be due to the higher $\mathrm{OH}^{-}$concentration of the thin water layer surrounding the particles compared to the bulk solvent $[38,39]$. However, we found that the disinfection activity of BiSCaO for both coliform bacteria (CF) and total viable cells (TC) was higher than that of SSP-Ca(OH) ${ }_{2}$ at identical $\mathrm{pH}[38,39]$, suggesting that the high disinfection activity of $\mathrm{BiSCaO}$ is due to a different mechanism. Several researchers reported that heated shell powders comprising mainly $\mathrm{CaO}$ had higher disinfection activity than those composed of mainly $\mathrm{Ca}(\mathrm{OH})_{2}$ for the deactivation and removal of biofilms of Escherichia coli [40] and Listeria species [19]. We hypothesized that a higher concentration of $\mathrm{OH}^{-}$in the thin aqueous surface layer of $\mathrm{Bis} \mathrm{CaO}$ particles might damage and kill various bacterial cells when $\mathrm{BiSCaO}$ particles come in contact with contaminated skin wound surfaces. Furthermore, heated SSP composed mainly of $\mathrm{CaO}$ but lacking $\mathrm{Ca}(\mathrm{OH})_{2}$ (i.e., $\mathrm{BiSCaO}$ ) was previously reported to generate reactive hydroxyl radical species, which may contribute to the stronger disinfection activity heated SSP compared to SSP-Ca $(\mathrm{OH})_{2}[19,40]$. Our preliminary experiment also confirmed that $\mathrm{BiSCaO}$ also generate hydroxyl radical species. Low levels of reactive oxygen species are conductive to normal wound healing, but excessive reactive oxygen species can hinder wound healing [36]. Therefore, concentration of BiSCaO ointment (0.2-1 wt $\%$ ) and time period ( 3 days) for the treatment should be limited to avoid the negative effects of $\mathrm{BiSCaO}$ on wound repair, as shown in this study. Thus, limited application of $0.2 \mathrm{wt} \% \mathrm{BiSCaO}$ ointment, not $5 \mathrm{wt} \%$, to the infected wounds for 3 days optimally enhanced both disinfection and wound healing.

Compared with basic $\mathrm{NaClO}$ solution, low concentrations of weakly acidic $\mathrm{HClO}$ solution (50-200 ppm) are reported to have excellent In Vitro bactericidal properties against Gram-positive organisms such as Staphylococcus aureus, Bacillus cereus and Bacillus subtilis, and Gram-negative bacteria such as $P$. aeruginosa [41,42]. However, weakly acidic $\mathrm{HClO}$ reacts readily with various $\mathrm{NH}_{2}$ - or $\mathrm{CHO}$-containing organic compounds (e.g., proteins, amino acids and carbohydrates), which can rapidly consume $\mathrm{HClO}$ in the vicinity of the infected wound $[25,43]$. A study demonstrated that $\mathrm{HClO}$ interacts with primary amino groups $\left(-\mathrm{NH}_{2}\right)$ in organic compounds such as amino acids, generating chloramine groups $\left(-\mathrm{NH}_{2} \mathrm{Cl}\right.$ or $\left.-\mathrm{NHCl}_{2}\right)$ that are known to have oxidizing properties and antimicrobial activity [44].

BiSCaO has not been approved by the Pharmaceuticals and Medical Devices Agency of Japan for use as a pharmaceutical or medical device, despite the approval of $\mathrm{NaClO}$ for such purposes. Additional systemic studies on $\mathrm{BiSCaO}$ are required to establish its efficacy, safety, and stability for medical use. Furthermore, since we have preliminary data which $0.2 \mathrm{wt} \% \mathrm{BiSCaO}$ suspension has bactericidal activity against methicillin-resistant Staphylococcus aureus (MRSA), the effects on MRSA would be investigated to apply this $\mathrm{BiSCaO}$ ointment for clinical practice.

\section{Materials and Methods}

\subsection{Preparation of BiSCaO Ointment}

Scallop shell powders with an average diameter of $6 \mu \mathrm{m}$ heated at $1450{ }^{\circ} \mathrm{C}(\mathrm{BiSCaO})$ were purchased from Plus Lab Corp., Kanagawa, Japan. According to the manufacturer, the content of $\mathrm{CaO}$ exceeded $99.5 \%$. BiSCaO ointments $(5,1,0.2$ and $0.04 \mathrm{wt} \%)$ were prepared by mixing well $\mathrm{BiSCaO}$ with white Vaseline (KENEI Pharmaceutical Co., Ltd., Osaka, Japan). (Figure 7). Povidone iodine ointment $\left(3 \mathrm{wt} \%\right.$ ISODINE $\left.{ }^{\circledR}\right)$ was purchased from Shionogi Co., Ltd., Osaka, Japan. 


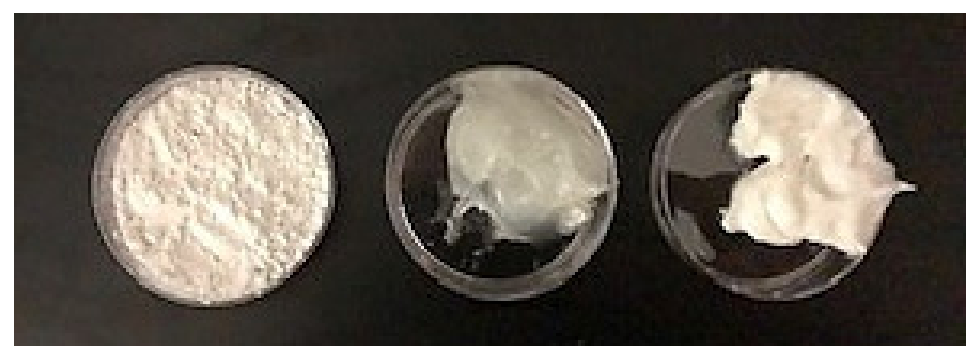

Figure 7. Appearance of BiSCaO (left), ointment (white Vaseline, middle) and $0.2 \mathrm{wt} \% \mathrm{BiSCaO}$ ointment (right).

\subsection{Bactericidal Activity of Various Concentrations of BiSCaO and Povidone Iodine Ointments In Vitro}

P. aeruginosa (American Type Culture Collection 27853, Manassas, VA, USA) colonies were stored at $-80{ }^{\circ} \mathrm{C}$ in Luria-Bertani broth containing $50 \%$ sterile glycerol and were freshly grown at a density of $1.0 \times 10^{6}$ colony forming units $(\mathrm{CFU}) / \mathrm{mL}$. Various concentrations of BiSCaO ointment, providone iodine ointment, and control ointment $(1 \mathrm{~mL})$ were coated onto $90 \times 15 \mathrm{~mm}$ Petri plates. P. aeruginosa suspension $(5 \mathrm{~mL})$ was added to each ointment-coated plate and incubated for 10,30 and $60 \mathrm{~min}$ at room temperature. Each P. aeruginosa suspension was plated onto $90 \times 15 \mathrm{~mm}$ Petri plates containing Pseudomonas isolation agar (Neogen Ltd., Lansing, MA, USA) and incubated at $37^{\circ} \mathrm{C}$ for $24 \mathrm{~h}$. The generated colonies were counted and disinfection activity was evaluated to determine in vitro bactericidal activity against $P$. aeruginosa.

\subsection{Applications of Various Concentrations of BiSCaO and Povidone Iodine Ointment to P. aeruginosa-Infected Wounds In Vivo}

All animal experiments were approved by the National Defense Medical College, Tokorozawa, Saitama, Japan, and were carried out following the relevant guidelines for animal experimentation (approval number, 17084, 18/2/2019). Hairless rats (male, 300-350 g) were obtained from Japan SLC Inc., Shizuoka, Japan and were maintained under appropriate conditions (i.e., $26{ }^{\circ} \mathrm{C}, 55 \%$ humidity). On nominal Day 0 of the study, the rats were placed under general anesthesia by intraperitoneal injection of pentobarbital sodium (Dainippon Sumitomo Pharma Co., Ltd., Osaka, Japan). Full-thickness round wounds were created on the back of each rat using a sterile $8 \mathrm{~mm}$ dermal punch (Kai Industries Co., Ltd., Oyana, Japan) and a pair of sterilized sharp scissors. To generate infected wounds, $100 \mu \mathrm{L}$ of growing $P$. aeruginosa was applied to the surface of each freshly generated wound, and each wound was covered with a piece of chitin nanofiber sheet (CNFS) approximately $30 \%$ deacetylated and obtained as a commercial product (BeschitinW, Nipro Corp., Osaka, Japan). The animals were returned to their cages and the wounds were visibly infected $24 \mathrm{~h}$ later. The P. aeruginosa-infected wounds were cleaned once daily by gentle rubbing 3 times using gauze dipped in $3 \mathrm{~mL}$ of saline (Ootsuka normal saline, Otsuka Pharmaceutical Factory, Inc. Tokushima, Japan), then $1 \mathrm{~mL}$ of $0.04 \mathrm{wt} \%, 0.2 \mathrm{wt} \%, 1 \mathrm{wt} \%$ or $5 \mathrm{wt} \% \mathrm{BiSCaO}$ ointment, $3 \mathrm{wt} \%$ providone iodine ointments, or control ointment was applied, then covered with CNFS for the first 3 days. On Days 4-9, all wounds in the 4 groups were cleaned with saline and covered with CNFS daily. The infected wounds in the non-cleaned group were only covered with CNFS without cleaning for the 9 days of the experimental period. After cleaning the wounds on Days 1, 2, 3, 6 and 9, the bioburden of each infected wound was determined by wiping with a strip of sterile $1 \mathrm{~cm}^{2}$ gauze. In the untreated group, the viable cells were counted after removal of the CNFS. The resulting cell suspensions were serially 10-fold diluted and $100 \mu \mathrm{L}$ aliquots of the diluted suspensions were plated onto $90 \mathrm{~mm} \times 15 \mathrm{~mm}$ Petri plates containing Pseudomonas isolation agar. The plates were incubated at $37^{\circ} \mathrm{C}$ for $24 \mathrm{~h}$; the viable cells confirmed to be P. aeruginosa by observation of their morphology were counted [26]. Digital photographs were recorded on Days 0, 1, 2, 3,6 and 9 and used to measure the rate of wound closure and to confirm the absence of complications, including acute inflammation, abscess formation, and seroma accumulation. 


\subsection{Histological Examination}

Following the post-cleaning collection of wound contents on Day 9, the animals were euthanized using pentobarbital sodium and the skin surrounding each infected wound, including wound tissue, was removed from each rat $(n=6)$ for histological examination. Skin samples from each treatment group were fixed in 10\% formaldehyde solution, embedded in paraffin, sectioned in $4 \mu \mathrm{m}$ increments (Yamato Kohki Inc., Asaka, Saitama, Japan) and used to generate $10 \times 1.5 \mathrm{~mm}$ sections perpendicular to the anterior-posterior axis and to the surface of the wound. These sections were transferred to glass slides for staining with hematoxylin-eosin (H\&E) reagent and for CD-34 immunostaining, covered with a cover slip, and evaluated microscopically. In each section $(n=8)$, the microscopic field showing the wound was photographed and the number of capillary lumens $\geq 10 \mu \mathrm{m}$ in diameter or containing $\geq 5$ erythrocytes was counted.

\subsection{Statistical Analyses}

Results were expressed as mean \pm standard deviations (SDs). Tukey's test was used to compare the disinfecting solutions. The statistical software JMP ${ }^{\circledR}$ (SAS Institute Inc., Tokyo, Japan) was used for the analyses. A value of $p<0.05$ was considered to be statistically significant.

\section{Conclusions}

In conclusion, treatment of $P$. aeruginosa-infected wounds on hairless rats by cleaning once a day with saline, applying $0.2 \mathrm{wt} \% \mathrm{BiSCaO}$ ointment for 3 days, and covering with CNFS significantly decreased the $P$. aeruginosa bioburden and enhanced wound repair.

Author Contributions: Conceptualization, T.T., M.I., S.N., Y.S., S.H., K.F., K.M., and H.Y.; methodology, T.T., S.N., Y.S., S.H., and K.F.; software, T.T., S.N., Y.S., S.H., and K.F.; validation, T.T., S.N., Y.S., S.H., and K.F.; formal analysis, T.T., S.N., Y.S., and S.H.; investigation, T.T., M.I., S.N., Y.S., S.H., K.F., K.M., and H.Y.; resources, M.I., K.F., K.M., and H.Y.; data curation, T.T., M.I., S.N., Y.S., K.F., S.H., K.M., and H.Y.; writing-original draft, T.T., M.I., S.N., K.M., and H.Y.; visualization, T.T., S.N., Y.S., and K.F.; supervision, M.I., K.M., and H.Y.; project administration, M.I., and H.Y.; funding acquisition, M.I., S.N., Y.S., K.M., and H.Y. All authors have read and agreed to the published version of the manuscript.

Funding: This study was partially supported by the Ministry of Education, Culture, Sports, Science and Technology of the Government of Japan (grant No. 19K15955).

Conflicts of Interest: The authors declare no conflict of interest.

$\begin{array}{ll}\text { Abbreviations } \\ \text { BiSCaO } & \text { bioshell calcium oxides } \\ \text { SSP } & \text { heated scallop shell powder } \\ \text { CNFS } & \text { chitin nanofiber sheets } \\ \text { Ag NP } & \text { silver nanoparticles } \\ \mathrm{HClO} & \text { hypochlorous acid } \\ \mathrm{CFU} & \text { colony forming units }\end{array}$

\section{References}

1. Clark, R.A.F. Biology of dermal wound repairs. Dermatol. Clin. 1993, 11, 647-666. [CrossRef]

2. Robson, M.C.; Stenberg, B.D.; Heggers, J.P. Wound healing alterations caused by infection. Clin. Plast. Surg. 1990, 17, 485-492.

3. Payne, W.G.; Wright, T.E.; Ko, F.; Wheeler, C.; Wang, X.; Robson, M.C. Bacterial degradation of growth factors. J. Appl. Res. 2003, 3, 35-40.

4. Serena, T.; Robson, M.C.; Cooper, D.M.; Ignatious, J. Lack of reliability of clinical/visual assessment of chronic wound infection: The incidence of biopsy-proven infection in venous leg ulcers. Wounds 2006, 18, 197-202.

5. Robson, M.C.; Edstrom, L.E.; Krizek, T.J.; Groskin, M.G. The efficacy of systematic antibiotics in the treatment of granulating wounds. J. Surg. Res. 1974, 16, 299-306. [CrossRef] 
6. Van Delden, C.; Iglewski, B.H. Cell-to-cell signaling and Pseudomonas aeruginosa infections. Emer. Infect. Dis. 1998, 4, 551-560. [CrossRef]

7. Wilson, J.P.; Mills, J.G.; Prather, I.D.; Dimitrijerich, S.D. A toxicity index of skin and wound cleaners used on in vitro fibroblasts and keratinocytes. Adv. Skin. Wound Care 2005, 18, 373-378. [CrossRef]

8. McCauley, R.L.; Linares, H.A.; Herndon, D.N.; Robson, M.C.; Heggers, J.P. In vitro toxicity of topical antimicrobial agents to human fibroblasts. J. Surg. Res. 1989, 3, 269-274. [CrossRef]

9. Kinoda, J.; Ishihara, M.; Hattori, H.; Fukuda, K.; Yokoe, H. Cytotoxicity of silver nanoparticle and chitin-nanofiber sheet composites caused by oxidative stress. Nanomaterials 2016, 6, 189. [CrossRef]

10. McCauley, R.L.; Li, Y.Y.; Poole, B.; Evans, M.J.; Robson, M.C.; Heggers, J.P.; Hemdon, D.N. Differential inhibition of human basal keratinocyte growth to silver sulfadiazine and mafenide acetate. J. Surg. Res. 1992, 52, 276-285. [CrossRef]

11. Wiercinski, F.J. Calcium, An overview-1989. Biol. Bull. 1989, 176, 195-217. [CrossRef] [PubMed]

12. Liu, F.J.; Chou, K.S.; Huang, Y.K. A novel method to make regenerable core-shell calcium-based sorbants. J. Environ. Manag. 2006, 79, 51-56. [CrossRef] [PubMed]

13. Sawai, J. Antimicrobial characteristics of heated scallop shell powder and its application. Biocontrol Sci. 2011, 1, 95-102. [CrossRef] [PubMed]

14. Watanabe, T.; Fujimoto, R.; Sawai, J.; Kikuchi, M.; Yahata, S.; Satoh, S. Antibacterial characteristics of heated scallop-shell nano-particles. Biocontrol Sci. 2014, 19, 93-97. [CrossRef]

15. Thammakarn, G.; Satoh, K.; Suguro, A.; Hakim, H.; Ruenphet, S.; Talehara, K. Inactivation of avian influenza virus, Newcastle disease virus and goose parvovirus using solution of nano-sized scallop shell powder. J. Vet. Med. Sci. 2014, 76, 1277-1280. [CrossRef]

16. Sawai, J.; Miyoshi, H.; Kojima, H. Sporicidal kinetics of Bacillus subtilis spores by heated scallop shell powder. J. Food Prot. 2003, 66, 1482-1485. [CrossRef]

17. Xing, R.; Qin, Y.; Guan, X.; Liu, S.; Yu, H.; Li, P. Comparison of antifungal activities of scallop shell, oyster shell and their pyrolyzed products. Egypt. J. Aqua. Res. 2013, 39, 83-90. [CrossRef]

18. Sawai, J.; Nagasawa, K.; Kikuchi, M. Ability of heated scallop-shell powder to disinfect Staphylococcus aureus biofilm. Food Sci. Technol. Res. 2013, 19, 561-568. [CrossRef]

19. Shimamura, N.; Irie, F.; Yamakawa, T.; Kikuchi, M.; Sawai, J. Heated scallop-shell powder treatment for deactivation and removal of Listeria sp. Biofilm formed at low temperature. Biocontrol Sci. 2015, 20, 153-157. [CrossRef]

20. Sato, Y.; Ishihara, M.; Nakamura, S.; Fukuda, K.; Takayama, T.; Hiruma, S.; Murakami, K.; Fujita, M.; Yokoe, H. Preparation and application of bioshell calcium oxide $(\mathrm{BiSCaO})$ nanoparticles-dispersions with bectericidal activity. Molecules 2019, 24, 3415. [CrossRef]

21. Sato, Y.; Ohata, H.; Inoue, A.; Ishihara, M.; Nakamura, S.; Fukuda, K.; Takayama, T.; Murakami, K.; Hiruma, S.; Yokoe, H. Application of colloidal dispersions of bioshell calcium oxide (BiSCaO) for disinfection. Polymers 2019, 11, 1991. [CrossRef] [PubMed]

22. Dissemond, J. Chronic wounds and bacteria. Clinical relevance, detection and therapy. Hautarzt 2014, 65, 10-14. [CrossRef]

23. Selim, P.; Bashford, C.; Grossman, C. Evidence-based practice: Tap water cleansing of leg ulcers in the community. J. Clin. Nurse 2001, 10, 372-379. [CrossRef] [PubMed]

24. Moore, Z.; Cowman, S. A systematic review of wound cleansing for pressure ulcers. J. Clin. Nurse 2008, 17, 1963-1972. [CrossRef] [PubMed]

25. Ishihara, M.; Murakami, K.; Fukuda, K.; Nakamura, S.; Kuwabara, M.; Hattori, H.; Fujita, M.; Kiyosawa, T.; Yokoe, H. Stability of weak acidic hypochlorous acid solution with microbicidal activity. Biocontrol Sci. 2017, 22, 223-227. [CrossRef]

26. Kim, H.J.; Lee, J.G.; Kang, J.W.; Cho, H.J.; Kim, H.S.; Byeon, H.K.; Yoon, J.H. Effects of a low concentration hypochlorous acid nasal irrigation solution on bacteria, fungi, and virus. The Laryngoscope 2008, 118, 1862-1867. [CrossRef]

27. Kuwabara, M.; Ishihara, M.; Fukuda, K.; Nakamura, S.; Murakami, K.; Sato, Y.; Yokoe, H.; Kiyosawa, T. Disinfection by Hypochlorous Acid for Pseudomonas aeruginosa-Infected Wounds in Diabetic db/db Mice. Wound Med. 2018, 23, 1-5. [CrossRef] 
28. Nguyen, V.Q.; Ishihara, M.; Kinoda, J.; Hattori, H.; Nakamura, S.; Ono, T.; Miyahira, Y.; Matsui, T. Development of antimicrobial biomaterials produced from chitin-nanofiber sheet/silver nanoparticle composites. J. Nanobiotechnol. 2014, 12, Art no. 49. [CrossRef]

29. Ishihara, M.; Nguyen, V.Q.; Mori, Y.; Nakamura, S.; Hattori, H. Adsorption of silver nanoparticles onto different surface structures of chitin/ chitosan and correlations with antimicrobial activities. Int. J. Mol. Sci. 2015, 16, 13973-13988. [CrossRef]

30. Nakamura, S.; Sato, M.; Sato, Y.; Ando, N.; Takayama, T.; Fujita, M.; Ishihara, M. Synthesis and application of silver nanoparticles (Ag nps) for the prevention of infection in healthcare workers. Int. J. Mol. Sci. 2019, 20, Art No. 3620. [CrossRef]

31. Kuwabara, M.; Sato, Y.; Takayama, T.; Nakamura, S.; Fukuda, K.; Murakami, K.; Yokoe, H.; Kiyosawa, T. Healing of Pseudomonas aeruginosa-infected wounds in diabetic $\mathrm{db} / \mathrm{db}$ mice by weakly acidic hypochlorous acid cleansing and silver nanoparticle/chitin nanofiber sheet covering. Wound Med. 2020, 28, Art. No. 100183. [CrossRef]

32. Takayama, T.; Ishihara, M.; Sato, Y.; Nakamura, S.; Fukuda, K.; Murakami, K.; Yokoe, H. Bioshell calcium oxide (BiSCaO) for cleansing and healing of pseudomonas aeruginosa-infected wounds in hairless rats. Bio-Med. Mater. Engineer. 2020, in press.

33. Galiano, R.D.; Michaels, J., 5th; Dobryansky, M.; Levine, J.P.; Gurtner, G.C. Quantitative and reproducible murine model of excisional wound healing. Wound Repair Regen. 2004, 12, 485-492. [CrossRef] [PubMed]

34. Ishihara, M.; Nakanishi, K.; Ono, K.; Sato, M.; Kikuchi, M.; Saitoh, Y.; Yura, H.; Matsui, T.; Hattori, H.; Uenoyama, M.; et al. Photocrosslinkable chitosan as a dressing for wound occlusion and acceletor in healing process. Biomaterials 2002, 23, 833-840. [CrossRef]

35. Ishihara, M.; Ono, K.; Sato, M.; Nakanishi, K.; Saitoh, Y.; Yura, H.; Matsui, T.; Hattori, H.; Fujita, M.; Kikuchi, M.; et al. Acceleration of wound contraction and healing with photocrosslinkable chitosan hydrogel. Wound Repair Regen. 2001, 9, 513-521. [CrossRef]

36. Xu, Z.; Han, S.; Gu, Z.; Wu, J. Advances and impact of antioxidant hydrogel in chronic wound healing. Adv. Healthcare Mater. 2020, 9, 1901502. [CrossRef]

37. Huang, J.; Chen, L.; Gu, Z.; Wu, J. Red jujube-incorporated gelatin methacryloyl (GelMA) hydrogels with anti-oxidation and immunoregulation activity for wound healing. J. Biomed. Nanotechnol. 2019, 15, 1357-1370. [CrossRef]

38. Sato, Y.; Ishihara, M.; Nakamura, S.; Fukuda, K.; Kuwabara, M.; Takayama, T.; Hiruma, S.; Murakami, K.; Fujita, M.; Yokoe, H. Comparison of various disinfectants on bactericidal activity under organic matter contaminated water. Biocontrol Sci. 2019, 24, 103-108. [CrossRef]

39. Fukuda, K.; Sato, Y.; Ishihara, M.; Nakamura, S.; Takayama, T.; Murakami, K.; Fujita, M.; Yokoe, H. Skin cleansing technique with disinfectant using improved high-velocity steam-air micro mist jet spray. Biocontrol Sci. 2020, 25, 35-39. [CrossRef]

40. Kubo, M.; Ohshima, Y.; Irie, F.; Kikuchi, M.; Sawai, J. Disinfection treatment of heated scallop-shell powder on biofilm of Escherichia coli ATCC 25922 surrogated for E. coli O157:H7. J. Biomater. Nanobiotechnol. 2013, 4, 10-19. [CrossRef]

41. Ono, T.; Yamashita, K.; Murayama, T.; Sato, T. Microbicidal effect of weak acid hypochlorous solution on various microorganisms. Biocontrol Sci. 2012, 17, 129-133. [CrossRef] [PubMed]

42. Sakarya, S.; Gunay, N.; Karakulak, M.; Ozturk, B.; Ertugrul, B. Hypochlorous acids: An ideal wound care agent with powerful microbicidal, antibiofilm, and wound healing potency. Wounds 2014, 26, 342-350.

43. Sato, Y.; Ishihara, M.; Fukuda, K.; Nakamura, S.; Murakami, K.; Fujita, M.; Yokoe, H. Behavior of nitrate nitrogen and nitrite nitrogen in drinking waters. Biocontrol. Sci. 2018, 23, 139-143. [CrossRef] [PubMed]

44. Gottardi, W.; Debabov, D.; Nagl, M. N-chloramine, a promising class of well-tolerated topical anti-infectives. Antimicrob. Agents Chemother. 2013, 57, 1107-1114. [CrossRef] [PubMed]

(C) 2020 by the authors. Licensee MDPI, Basel, Switzerland. This article is an open access article distributed under the terms and conditions of the Creative Commons Attribution (CC BY) license (http://creativecommons.org/licenses/by/4.0/). 